caused the houseboat to swing around in such a way that the machine was subjected to stresses which it was not expected that it would be subjected to, nor necessary that it be subjected to, in order to give it a test in free flight, and that the machine, exactly as it existed in December, 1903, was thoroughly capable of making a successful flight and demonstrating that it was the first machine constructed in the history of the world capable of successfully transporting a human. being through the air and being properly controlled in such flight. The tests at Hammondsport certainly demonstrated that the machine was capable of doing more than had ever been expected of it in the matter of carrying weight, and that the original engine with which it was equipped not only furnished sufficient power to enable it to carry its original weight, but also a greatly increased weight requiring considerably more than fifty per cent. more power than the original weight required, and that the claim is thoroughly well founded that it was the first machine built capable of safely transporting a human being through the air and being properly controlled in such flight.

From Mr. Glenn H. Curtiss.

Garden City,

New York.

\title{
THE TRIALS OF THE LANGLEY FLYING MACHINE AT HAMMONDS= PORT, N.Y.
}

I have read the proof of Mr. Brewer's Paper on the Langley Flying Machine. In the first paragraph Mr. Brewer quotes Lord Northcliffe as saying that " in the United States there have been long and persistent attempts to belittle the work of Orville and Wilbur Wright." I think Lord Northcliffe has been misinformed. Personally, I have always thought the Wrights are entitled to and have received full credit for having invented and built the first airplane to make successful flights. The Langley Flying Machine of 1903 did however fly in 1914 at Hammondsport, N.Y., in its original condition with its original motor and propellers with no alterations except the addition of floats and their necessary supports, weighing altog ether $350 \mathrm{lbs}$. On several occasions this original machine rose from the water and flew for a short distance, and there is at least one photograph of the machine in the air.

Some time prior to June, r9I4, I received a letter from Dr. Walcott, of the Smithsonian Institute, stating that an appropriation had been made by the Trustees. of the Institute for the expenses of having the original Langley Flying Machine of 1903, which had been wrecked in launching at that time, given a trial flight and asking if I cared to undertake the commission. As we had every facility for doing the work and were very much interested in learning what the Langley machine would do, I replied that I would accept the commission. The machine was shipped to Hammondsport and assembled for the trial. We fitted three pontoons, two forward and one aft. The two forward pontoons were placed in such a position under the forward wing so that the angle of the guy wires leading from the wings would be unchanged. It was, of course, necessary to remove the long post to which the lift wires had been attached when the machine was launched from the catapault. I personally made the early trials and succeeded several times in rising from the water and flying for a short distance, carrying the additional head resistance and weight of the pontoons and fittings, which latter we found was about 35 olbs. The dihedral wings gave excellent stability, and we were so pleased with the fact that we were able to fly the machine with this great amount of extra weight that we asked permission to instal a more powerful 'motor' with a direct drive propeller and make more extended flights. This installation was made and flights were then made with the machine by two of my assistants, 
Mr. Doherty and Mr. Johnson. Mr. Doherty made some flights in quite badly disturbed air.

The facts are that the Langley machine was not only flown with the same identical motor, propellers, wing surfaces and general construction, but carried the additional weight of 35 olbs., and still further that with increased motor power it flew and carried an added weight of about 8oolbs., including the extra weight of the motor.

Mr. Brewer did not make his presence known at Hammondsport, and I had no knowledge that he was there. I was afterwards told he had been sent there by the Wrights, to gather evidence for their suit to show that the Langley machine was not a practical flying machine.

GLENN H. CURTISS.

Mr. Griffith Brewer, replying to the discussion, thanked Colonel Ogilvie and Mr. Handley Page for the very kind things they had said about him. He would remind Mr. Handley Page that his paper was not a question of patents, but simply a question of facts. Mr. Orville Wright had no interest now in the American patent, and the British patent expired in $191 \%$. Langley made all his laboratory experiments with flat planes, as Mr. Handley Page said, and he apparently based his calculations on those flat surface experiments. His machine was built up and was a failure, and he recognised that it was a failure. Later on, eleven years afterwards, when interests with financial considerations came in, this historic relic, as Mr. Handley Page had said, was taken out of the Smithsonian Institution, where everyone respected it. It was cut into pieces; new wings were built, a new means for lateral control added, a different principle of trussing substituted, and, keeping most of these alterations in the background, it was reported to the Smithsonian Institution that this was the original machine. This new and changed machine was then put through trials to try to show that Langley's original machine would have succeeded if it had not met with an accident in launching, which " accident," he said, never occurred. It was the inevitable which took place - the collapse and fall of a machine which could not fly.

Referring to the letters received by the Secretary of the Royal Aeronautical Society from Dr. Walcott, Dr. Zahm, Mr. Manly and Mr. Curtiss, which arrived too late for reading at the lecture, Mr. Griffith Brewer says as follows :-

Replying generally to all four communications, I observe that they do not deny a single one of my statements of the changes made when building the Hammondsport machine, but merely dispute my conclusions. My statement that the Smithsonian Institution paid no more than the carriage of the machine to Hammondsport, however, appears to be contradicted. Dr. Walcott's statement ai first glance would be taken to say that two thousand dollars had been paid to Curtiss out of the Langley Aerodynamical Laboratory funds. On a careful reading of his statement it will be found that he does not say this. Nor does Dr. Walcott, in his reply, specifically deny the truth of my statement. I instituted an inquiry at the Smithsonian Institution when I was in America and I based my statement iil my paper upon the verbal assurance given by the Secretary's office that the Institution had paid only for the transport of the machine to Hammondsport; and also upon the statement of Mr. Orville Wright, who told me that Dr. Walcott himself had stated to him on the 2 Ist of April of this year that the Smithsonian had paid only for the transportation of the machine to Hammondsport.

In reply to Dr. Walcott's criticism on my paper, I would first like to thank him for the kindly manner in which he has discussed my arguments. I have no doubt that Wilbur and Orville Wright fully appreciated the recognition of the 
Smithsonian Institution when it conferred the award referred to by Dr. Walcott, for being the first to make actual flights in heavier-than-air power-propelled machines. When Dr. "Walcott, however, states that he is not prepared to concede that the Wrights were the first to construct such a machine capable of such flight, he is, of course, referring to the Langley machine, which was not capable of flight in 1903. Moreover, when this "recognition" was made to which Dr. Walcott refers, he had evidently not then decided to reserve to the Smithsonian Institution the honour of having originated the first machine capable of sustained free flight. This claim was only put forward in later years after Mr. Langley's death, and is apparently solely based on what was done at Hammondsport. My paper refers to the actual doings at Hammondsport and the actual aerodynamic differences between the Hammondsport machine and the machine built by $\mathrm{Mr}$. Langley, and I reiterate the case presented in my paper, that nothing done at Hammondsport has changed the situation. Langley designed and built a machine which failed to fly, and which anyone to-day with a knowledge of aerodynamics must know could not have flown. It makes no difference whether the Langley machine failed by breaking, or by want of balance, or because it bent out of shape so as to make it too inefficient to be flown, or irom lack of propeller thrust. If it failed for any one of these causes, or for the combined failure of all of them, it would not be a machine capable of flight. In the Hammondsport machine all these and other faults were guarded against, and even then no sustained flights were made.

Dr. Walcott says that I appear to claim that the guying of the wings, the changes made in the engine, the changes made in the propellers, the changes made in the form of wings, and the changes in the rudder, were each indispensable on the Hammondsport machine. Dr. Walcott seems to forget that the Smithsonian report which he has circulated so widely, suggests that these changes were indispensable, because it refers to the Hammondsport machine as "the Langley aeroplane kept as nearly as possible in its original condition." Obviously, therefore, the changes made by Mr. Curtiss were indispensable, for the original condition was preserved wherever it was possible to avoid change.

As Dr. Walcott does not specifically deny a single one of the changes which $I$ have enumerated in my paper, I think I am correctly giving the gist of his reply when I say that he expresses the belief, that because a machine with wings more roughly built and having a different camber, different area, different aspect ratio, different system of launching, different system of trussing, different weight, modified propellers, modified controls and with a modified motor had succeeded in getting off the water for approximately five seconds, therefore the original Langley machine of the original design and original construction should be able to fly.

Dr. Walcott seems to think it unfair that I quote Mr. Manly's statement made immediately after the tests of the original Langley machine as to the cause of the wreck, instead of a statement which he made in the Langley Memoir written some years afterward. However, the substance of this long quotation, which he gives from the Langley Memoir, is contained in the paragraph on page 624 of my paper, beginning with "After the machine had been recovered from the water," etc. I think that no impartial reader of my statement can say either that my quotation was garbled or that $I$ have omitted any important matter stated in the long quotation reproduced in Dr. Walcott's reply.

Dr. Walcott at the end of his letter criticises the diagram in my paper showing the machine at Hammondsport. This diagram is a true representation of the Hammondsport machine as it was in the trials to which Dr. Zahm devotes the most space in his report. But since the machine was modified many times it would be impossible to represent it in this paper as it was in all the different stages. 
The question of whether Dr. Walcott is prepared to concede that the Wrights were the first to construct a machine capable of sustained free flight does not concern the subject of my paper, because the decision on this point is not submitted to him for judgment. The claim of originating the first aeroplane capable of sustained free flight is put forward by Dr. Walcott after Mr. Langley's death as being due to his predecessor in the Smithsonian Institution, and he cannot pronounce judgment on this question and plead his claim at the same time.

Dr. Walcott touches the root of the argument when he claims these hops were "flights," because the official observer whom he appointed acknowledges that they were not really fights, because there was not sufficient propeller thrust. Flying may be compared to a person swimming. A person can either swim or he can't swim, and it is no use discussing how nearly he swims if he can't keep his head above water. An aeroplane can either fly or it can't fly, and it is no use discussing how nearly it flies if it has not enough propeller thrust to enable it to stay in the air as long as that amount of thrust lasts. The observer appointed by Dr. Walcott has stated that it was necessary to increase the propeller thrust. A Curtiss engine and a Curtiss propeller were therefore installed. The purpose of the propeller thrust was two-fold, i.e., (I) to propel the Hammondsport machine on the water, and (2) to make it fly. We are all agreed that the machine had sufficient propeller thrust to propel it on the water, so it was not necessary to increase the power for this purpose. It was, however, according to Dr. Zahm, necessary to increase the propeller thrust, and to make the Hammondsport machine fly was the only other object. It is therefore obvious that the increased thrust, which Dr. Zahm says was necessary, was to secure sustained flight, which had not been attained. Even when the power was nearly doubled by substituting the Curtiss engine and modern propeller for the old Langley engine and twin propellers it could not make the machine fly, but only enabled it to leave the water when headed into the wind between the lulls and assisted intermittently by the gusts of wind.

In reply to Dr. Zahm, we all appreciate that unnecessary personalities, innuendos, and imputations of bad faith should be avoided so far as it is possible to avoid them, but nothing can be gained by indirect language.

It is in starting from an unsound hypothesis that Dr. Zahm arrives at erroneous conclusions. His simile of the eagle and the baby is inapplicable to the Langley machine, because the eagle had flown before losing its feathers. The bird he must choose to correct the simile is the ostrich. Even a scientist of the type referred to by Dr. Zahm cannot prove that an ostrich will fly by merely pulling out some of its feathers, loading it with misplaced weight, and then assuming that the handicap imposed warrants the assumption that it would have flown if the poor bird had been left alone to begin with.

Dr. Zahm now acknowledges a change of the aspect of the wings. He says, "True, the overall aspect ratio had been increased slightly; but what was the gain in efficiency-three or four per cent.?" Dr. Zahm further acknowledges that the "arched leading edge" "was omitted at Hammondsport. A change in camber from one in twelve to one in eighteen made by these alterations improves an aeroplane surface of the Langley type by over twenty-five per cent. How can Dr. Zahm's acknowledgment now of these changes be reconciled with his statement that "the wings were identical in construction with the original machine, except, as I have heretofore stated, they were perhaps a little more roughly built and a little heavier."

Dr. Zahm now further acknowledges that the Hammondsport trials proved nothing as to the structural strength of the Langley machine. How does he reconcile his statement now with his previous statement in the Smithsonian Report which I have already quoted in my paper on page $63^{\circ}$, in which he pretends that 
the Langley trussing designed to carry $83^{\circ}$ pounds carried 1,520 pounds actual weight in the later tests?

Dr. Zahm is aware that his statement is untrue, and when his attention is drawn to it he is silent. It would be idle to further discuss Dr. Zahm's statement while these glaring discrepancies exist between his statements and the facts.

Coming to Mr. Manly's lengthy statement, I approach this with some diffidence, because of my admiration for his courage in attempting to pilot the original Langley machine in 1903 at imminent risk of his life. For a man with no flying experience, such as the later pilots of the Hammondsport machine had acquired after the Wrights built the first man-carrying aeroplane, he was bold beyond conception, especially so when he knew that the machine he was to test had so small a chance to fly.

Mr. Manly reiterates the reasons on which he based his belief that the failure of the Langley machine in 1903 was due to an accident to the launching gear. My review of the same evidence I contend clearly proves that Langley failed because his machine was not capable of flight. It is for independent readers of the Aeronautical Joursal to judge between us, and I venture to predict that the attempted flights of the Hammondsport machine in I9I4 will not strengthen the claim of the Smithsonian Institution.

Mr. Glenn H. Curtiss is content to reiterate that the Langley flying machine of 1903 did fly in 1914 at Hammondsport " in its original condition with its original motor and propellers with no alterations except the addition of floats and their necessary supports." I was not content in my paper to merely deny this statement which Mr. Curtiss has made many times before, but I produced photographs and other proof to show that the Hammondsport machine was not the Langley machine with merely these differences, and I also submitted proof that even with this amount of changing the machine did not fly. Mr. Curtiss's flat contradiction of the photographs given in my paper carries no weight, especially as Dr. Walcott, Dr. Zahm and Mr. Manly acknowledge the changes and do not support him in this contradiction.

A member of the Society has suggested that my paper related to a purely commercial dispute on patent rights which could be more suitably raised in a Law Court. A Court of Justice could not be invoked by me to judge whether the disclosures in my paper are true or false. Only at the instance of Dr. Walcott, Dr. Zahm, or Mr. Curtiss could the truth of these disclosures be judged in a Court. My paper has nothing to do with any patent rights, nor to any commercial consideration. I had no financial interest to serve in writing my paper, and I have no connection, and never have had any, with the American Company which owns. the American Wright patent.

To discuss the statements and conclusions given in such minute detail in these four letters would divert the issue from the real facts. The main purpose of my paper is to explode the fable that the Langley machine had been flown at Hammondsport. Neither Dr. Walcott, Dr. Zahm, nor Mr. Manly deny any of the changes pointed out in my paper. Mr. Curtis alone denies them, but he offers no proof to refute the photographs showing the changes he had made before the first trials. Dr. Walcott, Dr. Zahm, and Mr. Manly are content to contend that the changes were all made for some other purpose, which, far from helping the Hammondsport machine to fly, acted rather as a handicap. History does not want assumption and deductions. When a fact goes down to posterity, it must be based or: something that has been done, and even those associated with the Smithsonian Institution cannot be credited with deeds accomplished merely because of their high scientific standing and their belief that these deeds could have been done. By all means let Dr. Walcott, Dr. Zahm and Mr. Manly believe that Langley's machine 
would have flown if merely fitted with floats, handicapped with added weight, and with a skilled aviator in Mr. Manly's place. But they must stop there, and not say that the Langley rmachine has been flown, merely on the strength of their alleged belief that it could fly. No, the Langley machine is just where Langley left it-a beautifully executed delicate work suitable for a museum, but impossible in the air. It has never been flown and it never will fly.

[Editorial Note.-Correspondence is invited on the above lecture and discussion.]

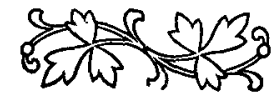

